\title{
Conceptualisation and measurement of Quality of Life based on Schalock \& Verdugo's model: A cross-disciplinary review of the literature
}

Nele Van Hecke, Claudia Claes, Wouter Vanderplasschen, Jessica De Maeyer, Nico De Witte en Stijn Vandevelde

\begin{abstract}
Researchers in the medical and social sciences have shown a rapidly growing interest in the concept of Quality of Life (QoL) in the past few decades. Reasons include its potential as an outcome measure of service delivery, and the opportunity of using a shared language both within and between different disciplines. Despite the widespread use of $\mathrm{QoL}$ in research, practice and policy development, there is little agreement on the defining aspects, as well as on the operationalization of the concept. In an attempt to broaden the knowledge on QoL and to give an overview of interdisciplinary consensus- and discussion aspects, a review of peer-reviewed QoLreviews, indexed in Web of Science, and published from 2000-2013 ( $\mathrm{n}=75)$ was carried out. Theoretical and measurement principles, derived from the QoL-framework of Schalock \& Verdugo (2002) were systematically explored. Results indicate a growing interdisciplinary consensus on QoL as (1) a multidimensional construct, (2) composed of both objective and subjective dimensions, (3) with an emphasis on the subjective evaluation of one's life circumstances, (4) which is dynamic in nature and (5) which can be influenced and enhanced by a variety of factors, implying a positive view on social services. Contrary, debate is still going on (1) the ideal method to assess QoL, (2) the use of proxies in QoL-measurement and (3) the preference for a general or on the contrary disease- or target group specific QoL-instrument.
\end{abstract}

\section{Introduction}

In the past decades, Quality of Life (QoL) has increasingly been studied in the fields of education, health care, social services and family studies (Schalock \& Verdugo 2002; Claes 2009; De Maeyer et al. 2010; Hambleton and Keeling 2009). The focus on QoL has had a significant impact on research and practice, both as a strengthsbased support paradigm for persons in vulnerable situations (De Maeyer et al. 2010) as well as a basis to evaluate program outcomes (Schalock et al. 2008a; Claes et al. 2009). Several theoretical QoL-frameworks have been developed in different areas, such as economics, medicine and the social sciences (Cummins 2005), each with their own specific conceptual underpinnings. As it is impossible to describe all of these theories, we will focus here on four influential models: (1) Cummins' theory of subjective wellbeing homeostasis (2005), (2) Felce \& Perry's QoL-model (1995; 1997), (3) the World Health Organization's Quality of Life Model (1995), and (4) Schalock \& Verdugo's QoL-model (2002).

Cummins' theory of subjective well-being homeostasis has been widely accepted and validated. The basic premise relates to the fact that subjective well-being (SWB) is managed by both an affective and a cognitive homeostatic system (Cummins \& Nistico 2002; Cummins 2005). This reflects the attempt to maintain a normal positive sense of well-being (Cummins 2009; 2010). The concept of SWB has a number of scientifically underpinned properties:

(1) it is generally positive, indicating that people usually tend to rate their own well-being higher than other people's well-being (Cummins 2005);

(2) it is highly stable, more specifically: extremely pleasant or unpleasant events can cause a short-term temporary change, but homeostasis will return people to their previous level of SWB soon (Cummins 2009);

(3) despite its stability, it is responsive to change, as homeostasis can be defeated by adverse life events, causing a drop in the level of SWB below its homeostatic range (Cummins 2009);

(4) the level of SWB is strongly genetically determined, implying that each person has a set-point for SWB. On a dissatisfied-satisfied continuum with a scale from 0 to 100, the average is around 75 for people in Western populations (Cummins 1998; Cummins et al. 2002);

(5) its relationship with resources - such as income - is non-linear, as the influence of such indicator variables depends on the level of concern an individual places on it, the strength of the perceived deficit in this area, as well as the homeostatic system and the compensatory influence of other life domains (Cummins 2005); and 
(6) when operationalized by means of the question "How satisfied are you with your life as a whole", its composition dominantly reflects a stable and positive mood state, also referred to as 'Homeostatically Protected Mood', rather than a cognitive evaluation of people's lives. The homeostatic system seeks to defend this state of SWB (Cummins 2009; Davern et al. 2007).

Felce and Perry's QoL model $(1995 ; 1997)$ has been used with persons with intellectual and multiple significant disabilities (Petry et al. 2005; 2007). Felce and Perry define and conceptualize QoL as "an overall general wellbeing that comprises objective descriptors and subjective evaluations of physical, material, social, and emotional wellbeing, together with the extent of personal development and purposeful activity, all weighted by a personal set of values" (Felce \& Perry 1995, p. 62). Three essential components can be discerned: objective life conditions on different life domains, subjective feelings of wellbeing on these domains, and personal values and aspirations regarding these domains. These components are in a constant dynamic interaction with each other, as changes in one of the components may induce changes in the other components. At the same time these three elements are able of evolving independently as a result of external influences, such as age and maturation, or social, economic and political variables (Felce \& Perry 1995). As the components can be influenced by external factors, any measurement of QoL should include the assessment of all three aspects (Felce \& Perry 1995).

The World Health Organization (WHO) has made important contributions in the field of QoL, more specifically in the field of Health Related Quality of Life. The WHO considers the subjective nature of the QoL-concept as its defining feature (WHOQOL Group 1995). As a result, the WHO proposes a measurement model, in which questions about individuals' functioning are complemented with global evaluation questions on this functioning, and highly personalized evaluation questions in terms of level of satisfaction or dissatisfaction (WHOQOL Group 1995). The WHO emphasizes the multidimensional nature of QoL, leading to the premise that QoLmeasurement should at least include three domains: (1) a physical domain, referring to individuals' perceptions on their physical status; (2) a psychological domain, referring to individuals' perceptions on their cognitive and affective state; and (3) a social domain, referring to individuals' perception of the interpersonal relationships and social roles (WHOQOL Group 1995). Furthermore, both positive and negative dimensions are seen as important components in their QoL-framework (WHOQOL Group 1995). The WHO defines QoL as “individuals' perception of their position in life in the context of the culture and value systems in which they live and in relation to their goals, expectations, standards and concerns. It is a broad ranging concept affected in a complex way by the person's physical health, psychological state, level of independence, social relationships, personal beliefs and their relationship to salient features of their environment" (WHOQOL Group 1995, p 1405).

Schalock \& Verdugo's QoL model (2002) has been extensively documented, both in relation to its formulation (e.g. Claes et al. 2009; Jenaro et al. 2005; Schalock \& Verdugo 2002; Verdugo \& Schalock 2009; and Schalock et al. 2016), its validation of the conceptual and measurement framework (e.g. Jenaro et al. 2005; Wang et al. 2010), and its implementation (e.g. Schalock et al. 2008b; van Loon et al. 2013) (see Gómez et al. 2011 for an overview of studies). The model has significantly impacted the field of intellectual and developmental disabilities (Gómez et al. 2011). Research on this QoL-model has mostly been carried out in the field of intellectual and closely related developmental disabilities, but, as Verdugo et al. (2012) point out, the model is increasingly being applied in other research areas as well, such as mental health, drug addiction, special education, ageing and physical disabilities, and with individuals who are at risk for social exclusion (e.g. Bowling \& Gabriel 2004; De Maeyer et al. 2009; Verdugo et al. 2010; Gómez et al. 2012).

This review is based on Schalock \& Verdugo's QoL-model (2002), as this framework (1) is currently being applied in different fields (e.g. De Maeyer et al. 2009; Gomez et al. 2012); (2) is evolving towards a theory (Schalock et al. 2016); (3) has been investigated in several empirical studies (Claes et al. 2009, 2012a, 2012b; Gomez et al. 2015, 2016; Van Loon et al. 2014); and (4) has recently, in a comparison of five QoL-models, been shown to have the best model fit in terms of its factor composition and hierarchical structure (Gomez et al. 2011).

Schalock \& Verdugo (2002) suggest not to define the QoL-concept as such, but rather to agree upon its core domains and indicators, and on a number of principles concerning its conceptualization and measurement. The QoL-domains are defined as "the set of factors composing personal well-being"; indicators are referred to as 
“domain specific perceptions, behaviors, or conditions that reflect a person's well-being" (Schalock \& Verdugo 2002, p. 14; Wang et al. 2005). The actual number of QoL-domains is less important than the recognition of the construct as a multi-element framework, reflecting life as a whole (Schalock \& Verdugo 2002). Based on an extensive review of the QoL literature across the areas of intellectual and developmental disabilities, special education, behavior and mental health, and aging, the QoL-model is composed of eight core domains: (1) emotional well-being, (2) interpersonal relations, (3) material well-being, (4) personal development, (5) physical well-being, (6) self-determination, (7) social inclusion, and (8) rights (Schalock et al. 2016). The core QoLdomains reflect three levels of systems; micro- (individual), meso- (organizational) and macrolevel (societal) in which people live, and which affect people's QoL (Schalock \& Verdugo 2002). The QoL-model has a broad and holistic focus on the person as a whole, distinguishing it from Health Related QoL (HRQoL), which has a more delimited focus on the impact of illness, disease or disability on the level of individual functioning.

The etic (universal) and emic (culture-bound) properties of this QoL-construct have been cross-culturally validated in terms of domain structure and stability (Bonham et al. 2004; Jenaro et al. 2005; Schalock et al. 2005; Wang et al. 2010). Emic refers to an insider-perspective of a given individual, group or culture, whereas etic refers more broadly to a cross-cultural perspective, in which one is looking for universal knowledge. Results indicate that QoL is important for all people (Verdugo et al. 2005) and that the core domains are the same for all people (etic properties), but the relative value and importance individuals place on them can show individual and cultural variability (emic properties) (Schalock \& Verdugo 2002; Jenaro 2005; Wang et al. 2010). For that reason, the assessment of QoL-domains is based on culturally sensitive objective and subjective indicators (Claes et al. 2009).

Wang and colleagues (2010) found evidence for the multidimensional QoL-construct, with eight first order factors and a single second order factor; a general factor of QoL that differentially influences the 8 first order factors. However, more recently, Gomez et al. (2011) found, in a comparison of five QoL-models that have been derived from the original Schalock and Verdugo QoL theory, that the eight first order correlated factors model as proposed by Schalock and Verdugo (2002), shows the best model fit in terms of its factor composition and hierarchical structure. It should be noted, however, that this study was based on an objective assessment of QoL, so a replication of this study when subjective assessment is applied would be insightful (Gomez et al. 2011). As a result of the growing knowledge, QoL is defined by Schalock et al. (2016) as "a multidimensional phenomenon composed of core domains that constitute personal well-being. These domains are influenced by personal characteristics and environmental factors. One's QoL is the product of these factors and can be impacted positively through quality enhancement strategies that encompass developing personal talents, maximizing personal involvement, providing individualized supports, and facilitating personal growth opportunities" (Schalock et al. 2016, p. 4-5).

Influencing factors - QoL is determined by variables that include objective living conditions, but also, and maybe even more important, include people's own perceptions of these conditions (Verdugo et al. 2005). Subjective measures - often operationalized in terms of satisfaction - are based on one's perspective (either from self-reports or reports of others), and objective measures are based on the direct observation of a person's life experiences and circumstances (Schalock et al. 2008a; Claes et al. 2009; Gomez et al. 2012). Both types of measurement provide complementary information, and can make a significant contribution to QoL-assessment (Claes et al. 2009; Buntinx \& Schalock 2010; Verdugo et al. 2005).

Dynamic concept - Schalock \& Verdugo (2002) see QoL as a dynamic concept, which can change over time and as a result of changing environments. Moreover, people's perception on their QoL, and on the domains that matter most to them, can change according to the life stage one is in (Schalock et al. 2002). However, if QoL is merely measured in terms of a person's level of satisfaction, it appears to be rather stable (Schalock et al. 2002). It should be noted that satisfaction is only one facet of the multidimensional QoL-construct. Objective measures such as functional assessment and social indicators (Schalock et al. 2002; Schalock 2004; Schalock et al. 2008a) are more susceptible to change.

Measurement format - The most appropriate kind of QoL-measurement format may vary according to the specific goals of the assessment. Likert-type rating scales, followed by various forms of questionnaires, are used most frequently to measure QoL (Verdugo et al. 2005), but QoL-measurement on the basis of a conversation format has been suggested as well (Claes et al. 2009). The most important issue in choosing the appropriate measurement format is to make sure that the respondent is able to fully understand all the questions. 
Self- vs. Proxy-report - Both self-reports and reports of others are needed, depending on the goals of the measurement (Buntinx \& Schalock 2010). Although proxy-reports are not a valid indicator of a person's own perception on his/her QoL, they can provide useful information that should be taken into account (Schalock et al. 2002), especially for those people who cannot rate their own QoL (Claes et al. 2012). It is argued that, in these cases, proxy ratings can best be done by family members, or other individuals who know the person well (Claes et al. 2012).

Claes et al. (2009, p. 63) provide an overview of the current characteristics of QoL-measurement in the field of intellectual disabilities, based on the work of Bonham et al. (2004) and Verdugo et al. (2005): “(a) its multidimensional nature involving core domains and indicators; (b) the use of a methodological pluralism that includes the use of subjective and objective measures; (c) the incorporation of a system's perspective that captures the multiple environments impacting people at the micro, meso, and macrosystems levels; and (d) the increased involvement of persons with intellectual disabilities in the design and implementation processes". There appears to be general consensus on these measurement characteristics in the broader field of social welfare studies as well (Claes et al. 2009). (cf. Table 1 and Table 2)

\section{Conceptual principles}

1. QoL is a multidimensional construct

2. The concept has etic (universal) and emic (culture bound) properties

3. QoL is composed of both an objective and a subjective component

4. QoL is seen from a system's perspective

5. QoL is dynamic, it can change over time

6. QoL is broader than merely the absence of disease (QoL $\neq$ Health Related QoL)

Table 1: Conceptual principles derived from the QoL-framework of Schalock \& Verdugo (2002)

\begin{tabular}{|l|}
\hline \multicolumn{1}{|c|}{ Measurement principles } \\
\hline 1. \\
2. Inthodological pluralism: involving different perspectives and contexts in the assessment \\
3. Both self-reports and proxy-reports are needed, depending on the goals of the measurement \\
4. QoL-measurement requires a combination of objective and subjective indicators \\
5. Different measurement formats are possible \\
6.
\end{tabular}
Table 2: Measurement principles derived from the QoL-framework of Schalock \& Verdugo (2002)

\section{Aims}

In this literature review, we aim to investigate similarities and differences in the conceptualization and measurement of QoL across different disciplines, based on the QoL-framework of Schalock \& Verdugo (2002). More specifically, this study investigates whether or not the conceptual and measurement QoL-principles in Table 1 and 2, derived from this model, are also endorsed in other disciplines.

\section{Methods}

A systematic review of the available scientific QoL-literature was carried out using Web of Science, which comprises medical as well as social sciences. The search for articles with 'Quality of Life' in the title (1) resulted in 49756 articles. As it is practically impossible to review all of these articles, the study was limited to review studies, which have the benefit that a great amount of information on a certain subject is clearly contained in one document. Using this selection criterion in Web of Science resulted in 1376 available publications. (2) We restricted the domains of interest by selecting disciplines that represent the broad welfare- 
and health sector, operationalized by the following categories ${ }^{1}$ used in Web of Science, which resulted in 491 available review articles on QoL:
Oncology / psychology / multidisciplinary sciences / health care sciences services / social sciences interdisciplinary / political science / gerontology / orthopaedics / psychiatry / women's studies / public environmental occupational health / psychology developmental / sociology / nursing / psychology multidisciplinary / behavioural sciences / rehabilitation / education special / environmental sciences / geriatrics gerontology / substance abuse / audiology speech language pathology / psychology applied / psychology educational / psychology experimental / social work / sport sciences / urban studies / psychology clinical

From this point on, every article was screened by the first author on the basis of title and abstract. Articles were retained if: (1) the conceptual aspect of QoL is mentioned in the title or in the abstract, or (2) when assessment of QoL is the subject of the article. Review studies that did not mention one of these topics in the title, nor in the abstract were removed from the literature selection. This step resulted in 167 articles.

In a next step, the remaining 167 review studies were independently screened by the first and second author of this manuscript, as a means of increasing the validity and reliability. Articles were retained in two cases: (1) if the conceptual framework of QoL was considered an important subject of the article, and not merely an introduction to the study, and (2) if (part of) the article related to QoL measurement-issues. Both researchers classified 125 out of 167 review articles in the same way, meaning they both either included or excluded the article, which is equivalent to an agreement percentage of $74,85 \%$. The articles that were classified in a different way by the two researchers, were discussed. To ensure that all relevant articles were included in our study, all articles that had been selected by one of the researchers, in addition to all articles that had been selected by both researchers, were retained. By applying this rule, 112 of the 167 articles were included. We decided to exclude all articles published before $2000(\mathrm{n}=17)$. This strict time demarcation was introduced as a consequence of the nature of review studies, which cover information from quite some time before the publication date. Furthermore only papers in English were retained, which led to the exclusion of 10 manuscripts. An additional four articles were excluded as QoL was not approached as individual QoL ('societal QoL' and 'family QoL'), two publications were books, and from four articles we could not become a full text version, even after contacting the authors. This selection process ultimately provides us with a literature basis consisting of 75 articles.

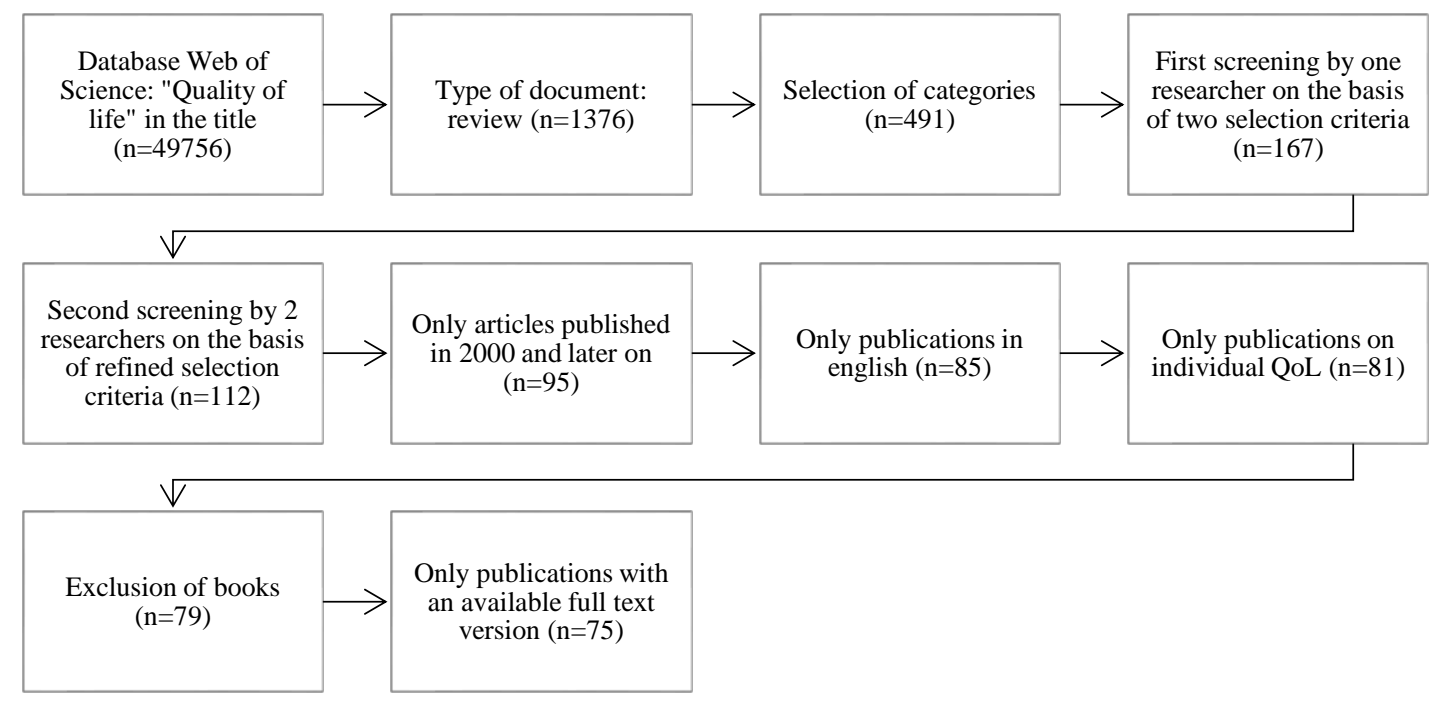

Figure 1: Flow diagram of the selection process

\footnotetext{
${ }^{1}$ The study was conducted by the centre of expertise on Quality of Life, E-QUAL, which is part of the Faculty of Education, Health and Social Work at Ghent University College. The chosen categories can be seen as a reflection of the departments.
} 
The 75 remaining articles were read in depth by the first author. Information concerning the conceptual and measurement principles derived from QoL-model by Schalock \& Verdugo (cf. Table 1 and Table 2), was filled out schematically in index cards per article, in order to enable comparison.

\section{Results}

\subsection{Conceptualization of QoL in different disciplines}

In Tables 3 and 4, publications are classified in the 'subscribed' group, if the authors explicitly mention and subscribe to a certain conceptual or measurement principle, or if the principle can clearly be deduced from the definition that is used. Furthermore, there is a classification group 'not reported' for the publications in which the conceptual or assessment principle has not been mentioned.

The most agreed upon principle appears to be that ' $Q o L$ is a multidimensional construct'. Only in $2,6 \%$ of the articles, QoL is operationalized as a unidimensional concept, measuring satisfaction with life as a whole. There seems to be some discussion on the third conceptual principle, stating that QoL is composed of both an objective and subjective component; in $16 \%$ of the articles QoL is considered as an exclusive subjective matter. Furthermore, QoL is often seen as a dynamic concept (42,7\%), which can change over time, and which can be influenced by several environmental factors $(38,7 \%)$. QoL is mostly seen as being broader than HRQoL (54,7\%). Some of the conceptual aspects (e.g. etic and emic properties, a system's perspective and the dynamic nature of the concept) have not been mentioned in a significant number of the reviewed publications.

\begin{tabular}{lccc}
\hline Conceptual principles & $\begin{array}{c}\text { Subscribed } \\
\text { to }\end{array}$ & Contradicted & $\begin{array}{c}\text { Not } \\
\text { Reported }\end{array}$ \\
\hline CP 1: QoL is a multidimensional construct & $82.7 \%$ & $2.6 \%$ & $14.7 \%$ \\
\hline CP 2: The concept has etic and emic properties & $28 \%$ & $0 \%$ & $72 \%$ \\
\hline CP 3: QoL is composed of both an objective and subjective component & $38.7 \%$ & $16 \%$ & $45.3 \%$ \\
\hline CP 4: QoL is seen from a system's perspective & $38.7 \%$ & $0 \%$ & $61.3 \%$ \\
\hline CP 5: QoL is dynamic & $42.7 \%$ & $0 \%$ & $57.3 \%$ \\
\hline CP 6: QoL is broader than HRQoL & $54.7 \%$ & $9.3 \%$ & $36 \%$ \\
\hline
\end{tabular}

Table 3: Number of publications $(n=75)$ in which the conceptual principles were either subscribed to, contradicted or have not been reported

\subsection{Measurement of QoL in different disciplines}

Overall, there has been little contradiction on the measurement principles. $72 \%$ of the studies comply to the principle of methodological pluralism. However, it cannot be deduced that authors of the reviewed publication agree with the assessment principles, as in many publications, these have not been explicitly mentioned (e.g. the aspects on involvement of the target group, and on the most appropriate measurement format). In most publications (60\%), there seems to be an even distribution over generic and age- or disease-specific instruments. Furthermore, authors mention that QoL can be measured using both objective and subjective standards (52\%), and that the use of proxies to gather information can be valuable, but whenever possible, the views of the persons themselves should be included in the measurement $(54,7 \%)$.

\begin{tabular}{lccc}
\hline Measurement principles & $\begin{array}{c}\text { Subscribed } \\
\text { to }\end{array}$ & Contradicted & $\begin{array}{c}\text { Not } \\
\text { Reported }\end{array}$ \\
\hline MP 1: Methodological pluralism & $72 \%$ & $1.3 \%$ & $26.7 \%$ \\
\hline MP 2: Involvement of target group & $34.7 \%$ & $0 \%$ & $65.3 \%$ \\
\hline MP 3: Both self-reports and proxy-reports are needed & $54.7 \%$ & $0 \%$ & $45.3 \%$ \\
\hline MP 4: Objective and subjective indicators & $52 \%$ & $0 \%$ & $48 \%$ \\
\hline MP 5: Different measurement formats are possible & $20 \%$ & $2.7 \%$ & $77.3 \%$ \\
\hline MP 6: Generic and age-, target group- or disease specific instruments & $60 \%$ & $12 \%$ & $28 \%$ \\
\hline
\end{tabular}

Table 4: Percentages of the publications $(n=75)$ in which the measurement principles were either subscribed to, contradicted, or have not been reported 
4.3 Qualitative information in relation to the conceptual and measurement principles

Multidimensionality - Central in most QoL-definitions that were retrieved in the review papers, is the multidimensionality of the construct. Our review shows that the definitions of 'health' and 'QoL' given by the World Health Organisation (WHO) are often used. Since most authors' conception of QoL is based on the WHO-definition, it can reasonably be assumed that they at least subscribe to a number of conceptual aspects inherent to this definition: i.e. the multidimensional nature of QoL, the importance of a subjective component, and the environmental influence on QoL.

Etic and emic properties of $Q o L$ - While there appears to be consensus on a number of QoL domains that are important for all people (e.g. physical, psychological and social dimensions), it is also stated that the relative value that is attached to these domains and their specific indicators differs for different groups of people, based on their own experience and frame of reference (Lanuza et al. 2000; Lau \& McKenna 2001). For instance, for people who lived in institutions for most of their lives, issues of privacy, autonomy and dignity may be very important, while this may not, or to a lesser extent, be the case for people who live independently, as they do not experience this as an issue (Hammell et al. 2004a).

Choice for a generic or specific QoL-instrument - Throughout different disciplines and target groups, both generic and disease- or age-specific QoL instruments are used to measure QoL (Upton et al. 2008; Savage et al. 2009). In the field of HRQoL, the advantage of disease-specific instruments relates to their sensitivity for changes in QoL during illness and its treatment (Savage et al. 2009). Age-, disease-, or target group specific instruments have the advantage to capture these life domains that are of specific importance for a certain group of people, while generic instruments might have the disadvantage of covering domains that are irrelevant for a certain group (Hammel 2004b; Halvorsrud and Kalfoss 2007; Jasovic-Gasic et al. 2010). To overcome these problems, some authors argue for generic instruments with more inclusive questioning - i.e. making wheelchair sport part of the response options (Sawin and Bellin 2010). Similarly, others argue that, in the context of comparability of scientific research, there is a need for generic QoL-instruments, with multiple modules for different age- and target-groups (Sprangers 2002; Nathan et al. 2004; Murphy et al. 2007; Jenkins et al. 2011; Panepinto and Bonner 2012).

Objective and subjective component, both in relation to conceptualization and measurement - There is a general agreement in the reviewed literature that QoL has both an objective and a subjective component (Ettema et al. 2005; Sprangers 2002). However, the subjective aspect of QoL often appears to be the essential characteristic of the QoL-construct (Prince and Prince 2001; Bloom et al. 2007; Jasovic-Gasic et al. 2010). Some authors even conceptualize QoL as an exclusively subjective concept and define it as the subjective perception of happiness and satisfaction in life-domains that matter to the individual (McDougall and Tsonis 2010; referring to Oleson 1990).

The great emphasis in the reviewed literature on the subjective aspect of QoL (McDougall and Tsonis 2009; Eiser 2009) is challenging as subjective perceptions are far less tangible than more concrete, objective parameters (Eiser 2009). Townsend-White and colleagues (2012) argue that every QoL-domain should be operationalized by separate measurable subjective and objective indicators. Some authors also argue that, when developing QoL-instruments, the personal preferences of people, more specifically the relative value one attaches to a certain life-domain, should be taken into account (Andresen and Meyers 2000).

System's perspective and dynamic nature of the concept - QoL is mostly referred to as a dynamic concept (Donohue 2002; Johnston and Miklos 2002; Sprangers 2002; Taylor et al. 2008), susceptible to changes, which can be influenced by a variety of personal, environmental and contextual factors (von Essen 2004; Ventegodt et al. 2007; Camfield and Skevington 2008; Fulton et al. 2012), such as certain life events, illness progress, coping abilities, or cultural changes (Moons et al. 2006). This reflects a positive view on the possibilities of care and service programs, as it implies that QoL can be enhanced, despite the existing pathology (Johnston and Miklos 2009). Likewise, QoL also evolves as a logical consequence of growing older and going through different developmental stages (Moons et al. 2006). As children and adolescents grow up, their values and priorities change, as well as their views of what contributes to a good life (Nathan et al. 2004; Moons et al. 2006, Savage et al. 2009; Klassen et al. 2011). This phenomenon is also referred to as the 'response shift model' (Sprangers \& Schwartz 1999). Even though QoL is generally seen as a dynamic concept, the subjective part of QoL, which is 
often measured in terms of satisfaction, is also said to fluctuate little from day to day (Moons et al. 2006). Central in this view, is the concept of 'homeostasis', stating that life events can induce temporarily changes in the experienced level of satisfaction, but people tend to return to a former state of wellbeing rather soon (Hensel 2001; Cummins 2005). In this regard, McDougall et al. (2010) also describe the 'disability paradox' in which people with severe disabilities have unexpectedly high QoL-scores. This is explained by the fact that every human being strives for a certain balance in life, and adapts his own frame of reference to the specific life conditions he is confronted with (McDougall et al. 2010).

QoL and HRQoL are different concepts - Several authors underscore the difference between QoL and HRQoL (e.g. Huebner et al. 2004; Moons et al. 2006; Fulton et al. 2012). As QoL is not solely determined by one's health status, HRQoL should be seen as an important, yet, only one of the multiple and interrelated QoLdomains (McDougall and Tsonis 2009). While QoL is focusing on individuals' subjective satisfaction with life as a whole and different life domains, HRQoL refers more limited to the absence of disease and pathology (De Maeyer et al. 2010), and focuses on the effects of a disease or health conditions on the daily functioning of individuals (Wiklund 2004). HRQoL encompasses domains such as physical, social, functional and psychological health; global QoL on the other hand is also influenced by economic-, environment-, living-, cultural- and religious factors (Lau and McKenna 2001). Notwithstanding the fact that in most investigated reviews there is a plea for a broader conception of QoL, the concept of QoL is mainly approached from a health related point of view.

Involvement of the target group in the development and implementation of QoL-instruments - In the reviewed literature, this principle has not been often referred to. Hammell (2004b) argues that the way in which a researcher measures QoL is more informative about the researcher's own values, priorities and fundamental orientation than it is about the situation of the persons that are investigated (Hammell 2007). Lindblad et al. (2002) and Hammell (2007) warn for the pitfalls associated with the use of QoL-instruments that are solely based on the opinion of clinicians and researchers. It is argued that, if one wants to include these domains and indicators that truly matter for people, it is of crucial importance that the people themselves are involved in the development of the instruments (Prince and Prince 2001; Taylor et al. 2008; McDougall and Tsonis 2009; Coghill et al. 2009). In this vein, a number of authors underscore the importance of clarifying and operationalizing the concept in close co-operation with the intended target group (Grange et al. 2007; PetersenEwert et al. 2011).

Self-reports and proxy-reports - There has been debate in the reviewed literature on the use of self- and proxyreports. Given the importance of the subjective component of QoL, with a high emphasis on the personal evaluation of life domains, most authors agree that QoL-assessment should primarily be done based on selfreports (Eiser and Morse 2001b; Donohue 2002; Nathan et al. 2004; von Essen 2004; Camfield and Skevington 2008; Upton et al. 2008; Coghill et al. 2009; Klassen et al. 2011). Proxy-reports can be considered as additional and possibly very relevant information, as long as they are not understood as the subjective rating of the individual himself (van Essen 2004; Nathan et al 2004). When considering proxy-reports it appears that the more concrete domains, like material and physical well-being lead to a greater degree of agreement than the more subjective domains, as emotional well-being and social inclusion (Eiser and Morse 2001b; von Essen 2004; Nathan et al. 2004; Varni et al. 2007). A problematic aspect of proxy-reports, is the fact that the people who mostly depend upon them, are often the ones who can express themselves the least due to communication problems, mental disorders, intellectual disabilities, ... (Nathan et al. 2004). In this group it is very difficult to examine the agreement between proxy and self-report, raising questions about the validity of these data (Nathan et al. 2004). Furthermore, not all proxy-reports seem to be equally accurate (Coghill et al. 2009). For example, in the case of children with ADHD, the agreement between parents and children is considerably larger than the agreement between children and clinicians (Coghill et al. 2009). A proxy that is not too closely involved in the daily care for the person, but who does maintain close contacts with the person, might be the most appropriate proxy (von Essen 2004).

Although self-reporting is mostly preferred, some authors also warn for associated pitfalls; self-reporting can be influenced by someone's mood, aspirations, and by the timing of the QoL-rating (Camfield and Skevington 2008). Furthermore, socially desirable answers could also bias the results of self-reports (Camfield and Skevington 2008). When working with children, there are a number of additional complicating factors: i.e. limited attention span, difficulties with negatively formulated items, difficulties with situating events in time, and 
a tendency to agree with the interviewer (Nathan et al. 2004). To overcome these problems, researchers increasingly argue for a QoL-instrument, in which several self- and proxy-perspectives are combined (Coghill et al. 2009; Danckaerts et al. 2010).

Measurement format - Most QoL-instruments seem to use Likert type-scales. However, this may not be the best option. Townsend-White and colleagues (2012), for instance, notice some methodological difficulties in measuring QoL of people with intellectual disabilities, as the validity and trustworthiness of using a Likert-scale is highly influenced by people's cognitive capacities. Currently, the pencil-paper format is often used for QoLinstruments, however, face-to-face interviews can be a valid way of evaluating one's QoL as well, and has the advantage that language skills and language comprehension are less problematic (Nathan et al. 2004; Coghill et al. 2009).

\section{Discussion}

In this study, we investigated the conceptualization and measurement of QoL in different disciplines in the broad health- and welfare sector, starting from a number of principles derived from Schalock \& Verdugo's QoL-model (2002). By doing so, we aimed to map similarities and differences in these disciplines. We believe this can be a first step in working towards a shared framework on QoL, and working towards interdisciplinary collaboration.

Most important results - The results of this literature review indicate that the way in which QoL is conceptualized and operationalized in several disciplines is quite similar on a number of principles. In general, there is considerable agreement on the following conceptual principles (Schalock \& Verdugo 2002): (1) the multidimensional nature of QoL, (2) that it consists of both an objective and a subjective component, (3) that it is influenced by several systems, (4) that it is dynamic in nature, and (5) that it has a broader and more holistic focus than HRQoL.

Similarly, there is considerable agreement on the following measurement principles: (1) the need for methodological pluralism, (2) the use of both self-reports and proxy-reports, with an emphasis on selfevaluation, (3) the use of both objective and subjective measures, and (4) the weighing of the choice for a general or a specific instrument.

However, the uniqueness of each discipline contributes to an ongoing debate and increased focus on some of the aforementioned aspects of QoL. In social disciplines for example, there is a relatively high emphasis on the need to develop instruments in close cooperation with the people for whom the instrument is intended, possibly driven by a strong belief in the importance of empowering people, giving voice to them and capturing and addressing those life domains that matter most to them. In medical disciplines, the importance of measuring QoL based on self-reports is highly emphasized. This may be due to the fact that the concept in these disciplines is mostly used to investigate the impact of a certain disease or treatment on the QoL of patients, and patients themselves are seen as the only reliable source of information to measure the experienced physical burden. Furthermore, QoLassessment in medical disciplines seems to have an increased emphasis on objective QoL-indicators, such as the level of functioning of a person, whereas social disciplines seem to be rather focusing on subjective indicators, such as satisfaction with several life domains. Both components play an important role in social and medical sciences, but they are emphasized differently. The choice for the most appropriate QoL measurement format has rarely been discussed in the reviewed literature, but if so, this seems to depend mostly on specific characteristics of the target group under study in both medical and social sciences.

Limitations - The results of this study should be interpreted in the context of some limitations. First, we studied the QoL-literature by means of a 'review of reviews'. The advantage of this method is that rich information is contained in one document, and that the vast QoL-literature becomes more manageable. However, the pitfall of this method is that the detailed descriptions and nuances of the original articles have already been processed and interpreted, which may lead to a loss of information. Further, our selection of the literature was limited in a number of ways: we only considered articles from Web of Science, we only considered articles from the year 2000 onwards, and we only considered articles that were published in English. Furthermore, our choice to review the QoL-literature, starting from the QoL-framework of Schalock \& Verdugo can be seen as a limitation of our study, as this might give the impression that this model is "superior" to other models, or that we see this model as the "golden standard". We chose the Schalock \& Verdugo model as a starting point, as this is a comprehensive and well-studied model, which we know from our own expertise in the field of intellectual and developmental disabilities. It is important, however, to note that this choice does not imply a value-judgement with regard to other QoL-models. 
Implications of our results - The results of this literature review have some implications for theory and practice. The review shows that most of the conceptual and measurement principles, derived from the QoL-framework of Schalock \& Verdugo (2002) are also endorsed by researchers from other disciplines, indicating that this QoLmodel might be useful for research and practice in other disciplines as well. This is in line with recent work by Schalock and colleagues (2016), in which they describe how their QoL-model is on its way to evolving towards a theory. One of the necessary steps in evolving from a model to a theory, is to demonstrate its generalizability. With regard to the assessment of QoL, the results of this review highlight the importance of always critically keeping in mind for whom one is creating a QoL-instrument. The content, as well as the measurement format should enable a valid QoL-assessment. QoL-measurement should thus include these indicators that are important for the individuals that are investigated. Qualitative research - for example on the basis of interviews or focus groups - in which people can freely define what a life full of quality means to them and what is needed for them to experience this, could further enhance our understanding of QoL. This could lead us to more valid results in QoL studies, as they are not based on a priori hypotheses, but on lived experiences. Furthermore, as there is general agreement on the dynamic nature of QoL, measurement instruments should be sensitive for evolutions or changes in QoL.

Concluding thought - The aim of our literature review was to look cross-disciplinary for similarities and differences in the conceptualization and measurement of QoL. We started our search by deriving a number of conceptual and measurement principles based on Schalock \& Verdugo's QoL-model (2002). This literature review is not a plea for the exclusive use of this specific model, as we realize that there are other valuable QoLmodels. Rather, it is an attempt to reach consensus on a number of principles concerning the conceptualization and measurement of QoL. 


\section{References}

Andresen, E.M., \& Meyers, A.R. (2000). Heath-related quality of life outcomes measures. Archives of Physical Medicine and Rehabilitation, 81(12), 30-45.

Ballinger, R.S., \& Fallowfield, L.J. (2009). Quality of life and patient reported outcomes in the older breast cancer patient. Clinical Oncology, 21, 140-155.

Bloom, J.R., Petersen, D.M., \& Kang, S.H. (2007). Multi-dimensional quality of life among long term (5+ years) adult cancer survivors. Psycho-Oncology, 16, 691-706.

Bonham, G.S., Basehart, S., Schalock, R.L., Marchand, C.B., Kirchner, N. \& Rumenap, J.M. (2004). Consumer based quality of life assessment: the Maryland Ask Me! project. Mental Retardation, 42, 338-355.

Bowling, A. \& Gabriel, Z. (2004). An integrational model of Quality of Life in older age. Results from the ESRC/MRC HSRC quality of life survey in Britain. Social Indicators Research, 69 (1), 1-36.

Buntinx, W.H.E. \& Schalock, R.L. (2010). Models of disability, Quality of Life, and Individualized Supports: Implications for Professional Practice in Intellectual Disability. Journal of Policy and Practice in Intellectual Disabilities, 7(4), 283-294.

Camfield, L. \& Skevington, S.M. (2008). On subjective well-being and quality of life. Journal of Health Psychology, 13, 764-775.

Charlemagne-Badal, S.J., Lee, J.W., Butler, T.L., Fraser, G.E. (2015). Conceptual domains included in wellbeing and life satisfaction instruments: A review. Applied Research in Quality of Life, 10, 305-328.

Claes, C., Van Hove, G., van Loon, J., Vandevelde, S. \& Schalock, R.L. (2009). Quality of life measurement in the field of intellectual disabilities: eight aspects for assessing quality of life-related personal outcomes. Social Indicators Research, 98, 61-72.

Claes, C., Van Hove, G., Vandevelde, S., van Loon, J., \& Schalock, R.L. (2012a). The influence of support strategies, environmental factors, and client characteristics on quality of life-related personal outcomes. Research in developmental disabilities, 33, 96-103.

Claes, C., Vandevelde, S., Van Hove, G., Van Loon, J., Verschelden, G., \& Schalock, R.L. (2012b). Relationship between self-report and proxy ratings on assessed personal Quality of Life-related outcomes. Journal of Policy and Practice in Intellectual Disabilities, 9(3), 159-163.

Coghill, D., Danckaerts, M., Sonuga-Barke, E., Sergeant, J. \& the ADHD European Guidelines Group, (2009). Practitioner review: quality of life in child mental health - conceptual challenges and practical choices. Journal of Child Psychology and Psychiatry, 50(5), 544-561.

Courtney, M., Edwards, H., Stephan, J., O’Reilly, M., \& Duggan, C. (2003). Quality of life measures for residents of aged care facilities: a literature review. Australasian Journal of Ageing, 22(2), 58-64.

Cummins, R.A. (1998). The second approximation to an international standard for life satisfaction. Social Indicators Research, 43(3), 307-334.

Cummins, R.A. \& Nistico, H. (2002). Maintaining life satisfaction: the role of positive cognitive bias. Journal of Happiness Studies, 3, 37-69.

Cummins, R.A. (2005). Moving from the quality of life concept to a theory. Journal of intellectual disability research, 49(10), 699-706.

Cummins, R.A. (2009). Measuring population happiness to inform public policy. Paper for the third OECD world forum on "statistics, knowledge and policy": charting progress, building visions, improving life. Busan, Korea.

Cummins, R.A. (2010). Subjective wellbeing, homeostatically protected mood and depression: a synthesis. Journal of Happiness Studies, 11, 1-17. 
Danckaerts, M., Sonuga-Barke, E.J.S., Banaschewski, T., Buitelaar, J., Döpfner, M., Hollis, C., Santosh, P., Rothenberger, A., Sergeant, J., Steinhausen, H.C., Taylor, E., Zuddas, A. \& Coghill, D. (2010). The quality of life of children with attention deficit/ hyperactivity disorder: a systematic review. European Child and Adolescent Psychiatry, 19, 83-105.

Davern, M., Cummins, R.A. \& Stokes, M. (2007). Subjective well-being as an affective-cognitive construct. Journal of Happiness Studies, 8, 429-449.

De Maeyer, J., Vanderplasschen, W., \& Broekaert, E. (2009). Exploratory study on drug users' perspectives on Quality of Life: more than health-related Quality of Life? Social indicators research, 90, 107-126.

De Maeyer, J., Vanderplasschen, W., \& Broekaert, E. (2010). Quality of life among opiate-dependent individuals: a review of the literature. International Journal of Drug Policy, 21(5), 364-380.

Diener, E. \& Tov, W. (2007). Subjective well-being and peace. Journal of Social Issues, 63(2), 421-440.

Donohue, P.K. (2002). Health-related quality of life of preterm children and their caregivers. Mental Retardation and Developmental Disabilities, 8, 293-297.

Eack, S.M., \& Newhill, C.E. (2007). Psychiatric symptoms and quality of life in schizophrenia: a meta-analysis. Schizophrenia Bulletin, 33(5), 1225-1237.

Eiser, C. (2009). Assessment of health-related quality of life after bone cancer in young people: easier said than done. European Journal of Cancer, 45, 1744-1747.

Eiser, C. \& Morse, R. (2001a). The measurement of quality of life in children: past and future perspectives. Journal on Developmental and Behavioural Pediatrics, 22(4), 248-256.

Eiser, C. \& Morse, R. (2001b). Can parents rate their child's health-related quality of life? Results of a systematic review. Quality of Life Research, 10(4), 347-357.

Ettema, T.P., Droës, R.M., de Lange, J., Ooms, M.E., Mellenbergh, G.J., \& Ribbe, M.W. (2005). The concept of quality of life in dementia in the different stages of the disease. International Psychogeriatrics, 17(3), 353-370.

Felce, D. (1997). Defining and applying the concept of Quality of Life. Journal of Intellectual Disability Research, 41(2): 126-135.

Felce, D. \& Perry, J. (1995). Quality of Life: its definition and measurement. Research in Developmental Disabilities, 16(1), 51-74.

Fitzsimmons, D., Gilbert, J., Howse, F., Young, T., Arrarras, J.I., Brédart, A., Hawker, S., George, S., Aapro, M., \& Johnson, C.D. (2009). A systematic review of the use and validation of health-related quality of life instruments in older cancer patients. European Journal of Cancer, 45, 19-32.

Fulton, J.S., Miller, W.R., \& Otte, J.L. (2012). A systematic review of analyses of the concept of quality of life in nursing. Exploring how form of analysis affects understanding. Advances in nursing science, 35(2), E1-E12.

Grange, A., Bekker, H., Noyes, J., \& Langley, P. (2007). Adequacy of health related quality of life measures in children under 5 years old: a systematic review. Journal of advanced nursing, 59(3), 197-220.

Gomez, L.E., Verdugo, M.A., Arias, B. \& Arias, V. (2011). A comparison of alternative models of individual Quality of Life for social service recipients. Social Indicators Research, 101, 109-126.

Gomez, L.E., Arias, B., Verdugo, M.A., \& Navas, P. (2012). An outcomes-based assessment of quality of life in social services. Social Indicators Research, 106, 81-93.

Gomez, L.E., Arias, B., Verdugo, M.A., Tassé, M.J., \& Brown, I. (2015). Operationalisation of quality of life for adults with severe disabilities. Journal of Intellectual Disability Research, 10, 925-941.

Gomez, L.E., Pena, B., Arias, B., \& Verdugo, M.A. (2016). Impact of individual and organization variables on quality of life. Social Indicators Research, 125, 649-664. 
Halvorsrud, L., \& Kalfoss, M. (2007). The conceptualization and measurement of quality of life in older adults: a review of empirical studies published during 1994-2006. European Journal of Ageing, 4, 229-246.

Hambleton, P., \& Keeling, S. (2009). The jungle of quality of life: mapping measures and meanings for elders. Australasian Journal of Ageing, 28(1), 3-6.

Hammell, K.W. (2004a). Quality of life among people with spinal cord injury living in the community. Spinal Cord, 42, 607-620.

Hammell, K.W. (2004b). Exploring quality of life following high spinal cord injury: a review and critique. Spinal Cord, 42, 491-502.

Hammell, K.W. (2007). Quality of life after spinal cord injury: a meta-synthesis of qualitative findings. Spinal Cord, 45, 124-139.

Hensel, E. (2001). Is satisfaction a valid concept in the assessment of quality of life of people with intellectual disabilities? A review of the literature. Journal of Applied Research in Intellectual Disabilities, 14, 311-326.

Huebner, E.S., Valois, R.F., Suldo, S.M., Smith, L.C., McKnight, C.G., Seligson, J.L. \& Zullig, K.J. (2004). Perceived quality of life: a neglected component of adolescent health assessment and intervention. Journal of Adolescent Health, 34, 270-278.

IsHak, W.W., Brown, K., Aye, S.S., Kahloon, M., Mobaraki, S., \& Hanna, R. (2012). Health-related quality of life in bipolar disorder. Bipolar Disorders, 14(1), 6-18.

Jasovic-Gasic, M., Lackovic, M., Dunjic-Kostic, B., Pantovic, M.M., Cvetic, T., Damjanovic, A., Vukovic, O., Cokovic, J., \& Jovanovic, A.A. (2010). Critical review of studies on quality of life in psychiatric patients published in serbian medical journals from 2000 to 2009. Psychiatria Danubina, 22(4), 288-294.

Jenaro, C., Verdugo, M.A., Caballo, C., Balboni, G., Lachapelle, Y., Otrebski, W., \& Schalock, R.L. (2005). Cross-cultural study of person-centred quality of life domains and indicators: a replication. Journal of Intellectual Disability Research, 9(10), 734-739.

Jenkins, P.E., Hoste, R.R., Meyer, C., \& Blissett, J.M. (2011). Eating disorders and quality of life: a review of the literature. Clinical Psychology Review, 31(1), 113-121.

Johnston, M.V., \& Miklos, C.S. (2002). Activity-related quality of life in rehabilitation and traumatic brain injury. Archives of Physical Medicine and Rehabilitation, 83(12), 26-38.

Klassen, A.F., Anthony, S.J., Khan, A., Sung, L. \& Klaassen, R. (2011). Identifying determinants of quality of life of children with cancer and childhood cancer survivors: a systematic review. Supportive Care in Cancer, 19, 1275-1287.

Lanuza, D.M., Faan, R.N., Lefaiver, C.A., \& Farcas, G.A. (2000). Research on the quality of life of lung transplant candidates and recipients: an integrative review. Heart \& Lung, 29(3), 180-195.

Lau, A., \& McKenna, K. (2001). Conceptualizing quality of life for elderly people with stroke. Disability and Rehabilitation, 23(6), 227-238.

Lindblad, A.K., Ring, L., Glimelius, B., \& Hansson, M.G. (2002). Focus on the individual: quality of life assessments in oncology. Acta Oncologica, 6, 507-516.

McDougall, J. \& Tsonis, M. (2009). Quality of life in survivors of childhood cancer: a systematic review of the literature (2001-2008). Supportive Care in Cancer, 17, 1231-1246.

Moons, P., Budts, W. \& De Geest, S. (2006). Critique on the conceptualisation of quality of life: a review and evaluation of different conceptual approaches. International Journal of Nursing Studies, 43, 891-901.

Murphy, B.A., Ridner, S., Wells, N., \& Dietrich, M. (2007). Quality of life research in head and neck cancer: a review of the current state of the science. Critical Reviews in Oncology / Hematology, 62, 251-267.

Namjoshi, M.A. \& Buesching, D.P. (2001). A review of the health related Quality of Life literature in bipolar disorder. Quality of Life Research, 10, 105-115. 
Nathan, P.C., Furlong, W. \& Barr, R.D. (2004). Review: challenges to the measurement of health-related quality of life in children receiving cancer therapy. Pediatric Blood and Cancer, 43, 215-223.

Oleson, M. (1990). Subjectively perceived quality of life. International Journal of Nursing Education Scholarship, 22, 187-190.

Panepinto, J.A., \& Bonner, M. (2012). Health-related quality of life in sickle cell disease: past, present and future. Pediatric Blood and Cancer, 59, 377-385.

Petersen-Ewert, C., Erhart, M., \& Ravens-Sieberer, U. (2011). Assessing health-related quality of life in European children and adolescents. Neuroscience and Behavioral Reviews, 35, 1752-1756.

Petry, K, Maes, B. \& Vlaskamp, C. (2005). Domains of quality of life of people with profound multiple disabilities: the perspective of parents and direct support staff. Journal of Applied Research in Intellectual Disabilities, 18, 35-46.

Petry, K, Maes, B. \& Vlaskamp, C. (2007). Support characteristics associated with the quality of life of people with profound intellectual and multiple disabilities: The perspective of parents and direct support staff. Journal of Policy and Practice in Intellectual Disabilities, 4, 104-110.

Prince, P.N., \& Prince, C.R. (2001). Subjective quality of life in the evaluation of programs for people with serious and persistent mental illness. Clinical Psychology Review, 21(7), 1005-1036.

Reinders, H.S. \& Schalock, R.L. (2014). How organizations can enhance the Quality of Life of their clients and assess their results: the concept of QoL enhancement. American Journal on Intellectual and Developmental Disabilities, 119(4), 291-302.

Savage, E., Riordan, A.O. \& Hughes, M. (2009). Quality of life in children with acute lymphoblastic leukaemia: a systematic review. European Journal on Oncology Nursing, 13, 36-48.

Sawin, K.J., \& Bellin, M.H. (2010). Quality of life in individuals with spina bifida: a research update. Developmental Disabilities Research Reviews, 16, 47-59.

Schalock, R.L. \& Verdugo, M.A. (2002). Handbook on Quality of Life for human service practitioners. Washington DC: American Association on Mental Retardation.

Schalock, R.L., Brown, I., Brown, R., Cummins, R.A., Felce, D., Matikka, L., Keith, K.D. \& Parmenter, T. (2002). Conceptualization, measurement, and application of Quality of Life for Persons with Intellectual Disabilities: Report of an International Panel of Experts. American Association on Mental Retardation, 40(6), 457-470.

Schalock, R.L. (2004). The concept of quality of life: what we know and do not know. Journal of Intellectual Disability Research, 48(3), 203-216.

Schalock, R.L., Verdugo, M.A., Jenaro, C., Wang, M., Wehmeyer, M., Xu, J., \& Lachapelle, Y. (2005). A crosscultural study of core quality of life domains and indicators. American Journal on Mental Retardation, 110, 298311.

Schalock, R.L., Bonham, G.S., \& Verdugo, M.A. (2008a). The conceptualization and measurement of quality of life: Implications for program planning and evaluation in the field of intellectual disabilities. Evaluation and program planning, 31, 181-190.

Schalock, R.L., Verdugo, M.A., Bonham, G.S., Fantova, F., \& van Loon, J. (2008b). Enhancing Personal Outcomes: Organizational Strategies, Guidelines, and Examples. Journal of Policy and Practice in Intellectual Disabilities, 5, 276-285.

Schalock, R.L., Verdugo, M.A., Gomez, L.E., \& Reinders, H. (2016). Moving us toward a theory of individual Quality of Life. American Journal on Intellectual and Developmental Disabilities, 121(1), 1-12.

Sprangers, M.A.G. (2002). Quality of life assessments in oncology: achievements and challenges. Acta Oncologica, 41(3), 229-237. 
Sprangers, M.A.G., \& Schwartz, C.E. (1999). Integrating response-shift into health related-quality of life research: a theoretical model. Social Science and Medicine, 48(11), 1507-1515.

Taillefer, M.C., Dupuis, G., Roberge, M.A. \& Le May, S. (2003). Health related quality of life models: systematic review of the literature. Social Indicators Research, 64, 293-323.

Taylor, R.M., Gibson, F. \& Franck, L.S. (2008). A concept analysis of health-related quality of life in young people with chronic illness. Journal of Clinical Nursing, 17(14), 1823-1833.

Townsend-White, C., Pham, A.N.T. \& Vassos, M.V. (2012). A systematic review of quality of life measures for people with intellectual disabilities and challenging behaviours. Journal of Intellectual Disability Research, 56(3), 270-284.

Upton, P., Lawford, J. \& Eiser, C. (2008). Parent-child agreement across child health-related quality of life instruments: a review of the literature. Quality of Life Research, 17(6), 895-913.

Van Loon, J., Claes, C., Vandevelde, S., Van Hove, G., \& Schalock, R.L. (2010). Assessing individual support needs to enhance personal outcomes. Exceptionality: a special education journal, 18, 193-202.

Van Loon, J., Bonham, G., Peterson, D.D., Schalock, R.L., Claes, C. \& Decramer, A. (2013). The use of evidence-based outcomes in systems and organizations providing services and supports to persons with intellectual disability. Evaluation and program planning. 36(1), 80-87.

Van Loon, J., Claes, C. \& Schalock, R.L. (2014). Improving quality of life, fulfilling rights: the use of the POSA in support plans for people with ID. Journal of Applied Research in Intellectual Disabilities, 27(4), 351.

Varni, J.W., Limbers, C. \& Burwinkle, T.M. (2007). Literature review: Health-related quality of life measurement in pediatric oncology: hearing the voices of the children. Journal of Pediatric Psychology, 32(9), 1151-1163.

Ventegodt, S., Kandel, I. \& Merrick, J. (2007). Quality of life and philosophy of life determines physical and mental health: status over research findings from the quality of life research center, Copenhagen, 1991-2007. The Scientific World Journal, 7, 1743-1751.

Verdugo, M.A., Schalock, R.L., Keith, K.D. \& Stancliffe, R.J. (2005). Quality of life and its measurement: important aspects and guidelines. Journal of Intellectual Disability Research, 49(10), 707-717.

Verdugo, M.A. \& Schalock, R.L. (2009). Quality of life: from concept to future applications in the field of intellectual disabilities. Journal of Policy and Practice in Intellectual Disabilities, 6(1), 62-64.

Verdugo, M.A., Arias, B., Gomez, L.E., \& Schalock, R.L. (2010). Development of an objective instrument to assess Quality of Life in social services: reliability and validity in Spain. International Journal of Clinical and Health Psychology, 10(1), 105-123.

Verdugo, M.A., Navas, P., Gómez, L.E. \& Schalock, R.L. (2012). The concept of quality of life and its role in enhancing human rights in the field of intellectual disability. Journal of Intellectual Disability Research, 56(11), 1036-1045.

Verdugo, M.A., Navas, P., Gómez, L.E. \& Schalock, R.L. (2014). The concept of quality of life in enhancing human rights in the field of intellectual disability. Journal of Intellectual Disability Research, 56(11), 10361045 .

von Essen, L. (2004). Proxy ratings of patient quality of life: factors related to patient-proxy agreement. Acta Oncologica, 43(3), 229-234.

Wang, M., Schalock, R.L., Verdugo, M.A. \& Jenaro, C. (2010). Examining the factor structure and hierarchical nature of the quality of life construct. American Journal on Intellectual and Developmental Disabilities, 115(3), 218-233.

WHOQOL Group. (1995). The World Health Organization Quality of Life Assessment (WHOQOL): Position paper from the World Health Organization. Social Science and Medicine. 41(10), 1403-1409. 
Wiklund, I. (2004). Assessment of patient-reported outcomes in clinical trials. The example of health-related quality of life. Fundamental \& Clinical Pharmacology, 18(3), 351-363.

Zekovic, B. \& Renwick, R. (2003). Quality of life for children and adolescents with developmental disabilities: review of conceptual and methodological issues relevant to public policies. Disability and Society, 18(1), 19-34. 